\title{
Effects of denture cleansers on Candida albicans biofilm and physical property of denture base materials
}

\author{
Min-Young Ko', Hyun-Jun Yoo', Myung-Gu Lee ${ }^{2}$, Yeol-Mae Jeon ${ }^{1}$, Da-Hui Kim ${ }^{3}$, Sung-Gin Kim', \\ Ja-Won Cho' \\ ${ }^{1}$ Department of Preventive Dentistry, College of Dentistry, Dankook University, Cheonan, Republic of Korea \\ ${ }^{2}$ College of Biomedical \& Health Science, Department of Biomedical Chemistry, Konkuk University, Chungju, Republic of Korea \\ ${ }^{3}$ Department of Dental Hygiene, College of Health Science, Dankook University, Cheonan, Republic of Korea
}

Objectives: The aims of this study were to investigated and compared antifungal activity of commercial denture cleansers sold in Korea against $C$. albicans biofilm and to analyze change of physical properties of denture base acrylic resin by the denture cleansers.

Methods: The specimen of denture base material was fabricated using polymethylmethacrylate acid according to the manufacturer's protocols to use formation of $C$. albicans and physical analysis. C. albicans biofilm was formed on the denture base acrylic resin using Ham's F-12 medium in 5\% $\mathrm{CO}_{2}$ incubator. The biofilms were treated with denture cleansers such as ClinicDent, DENTFIX, Polident ${ }^{\circledR}$, and Good habit according to manufacturer's instructions, and the suspension of C. albicans was inoculated on agar plate after disrupting the biofilm. The colonies were counted after incubating the plate. The denture base acrylic resin was treated with the denture cleansers for 90 days and analyzed surface roughness, surface hardness, and color change by atomic force microscope, Vickers micro hardness, and colorimeter, respectively.

Results: Polident ${ }^{\circledR}$ and Good habit showed the strongest antifungal activity against $C$. albicans biofilm, and DENTFIX has the weakest antifungal activity against the biofilm compared to the others. The denture cleansers used in this study significantly increased the surface roughness of the denture base acrylic resin $(p<0.05)$. In case of surface hardness, Polident ${ }^{\circledR}$ and Good habit significantly reduced more compared to control as tap water $(\mathrm{p}<0.05)$.

Conclusion: The significant difference of physical change among the denture cleansers treated the denture base acrylic resins did not show, and Polident ${ }^{\circledR}$ and Good habit has strong antifungal activity against $C$. albicans biofilm than the others. Based on the results, Polident ${ }^{\mathbb{R}}$ and Good habit may be suitable for use of denture wearers.

Key Words: denture cleansers, Candida albicans, biofilm

Copyright (C) 2021. Korean Academy of Preventive Dentistry. All rights reserved.

This is an Open Access article distributed under the terms of the Creative Commons Attribution Non-Commercial License (http://creativecommons.org/licenses/ by-nc/4.0) which permits unrestricted non-commercial use, distribution, and reproduction in any medium, provided the original work is properly cited. 